\title{
VARIATION OF ROOTS IN THE FORMATION OF MEDIAN NERVE
}

\author{
Vinay Sharma, C.S. Ramesh Babu *, Vishnu Gupta.
}

${ }_{1,{ }^{*} 2}$ Associate Professor, Department of Anatomy, Muzaffarnagar Medical College, Muzaffarnagar, UttarPradesh, India.

${ }^{3}$ Professor, Department of Anatomy, Muzaffarnagar Medical College, Muzaffarnagar, UttarPradesh, India.

\section{ABSTRACT}

Background: Median nerve formation exhibits several variations in the form of additional roots and /or communications which are relevant to the surgical explorations of shoulder, axilla and arm.

Aim: To study the variations in the formation of median nerve and its communications with musculocutaneous nerve in cadaveric upper limbs.

Materials and Methods: The study was done in 34 formalin fixed cadavers (68 upper limbs) and 10 isolated limbs. All cadavers were conventionally dissected and observed for median nerve formation and dissected up to cubital fossa for presence of any communications.

Observations: Out of the 78 upper limbs dissected, 12 limbs (15.38\%) showed two lateral roots and one medial root contributing to the formation of median nerve. One case of bilateral presence of extra lateral root was found. The extra lateral root or communication from the musculocutaneous nerve was arising distal to coracobrachialis in 2 cases and proximal to the muscle in 10 cases. In three cases, absence of musculocutaneous nerve was observed and median nerve was supplying either all or some muscles of the flexor compartment. One of the cases of absent musculocutaneous nerve had two medial roots and one lateral root that is a very rare combination of variation not reported in the literature. In all cases of two lateral roots, the median nerve was formed medial or anterior to axillary artery. So we observed median nerve variation in 16 upper limbs [20.51\%] Conclusion: Thorough understanding of variations in the formation and communications of median nerve and its vascular relations is important for successful surgical outcome and clinical interpretation of lesions of the nerve.

KEY WORDS: Median nerve, Musculocutaneous nerve, Double lateral roots, Double medial roots

Address for Correspondence: C.S. Ramesh Babu, M.Sc., Associate Professor of Anatomy, Muzaffarnagar Medical College, N.H. 58, Opp. Begrajpur Industrial Area, Muzaffarnagar- 251203, UttarPradesh, India. Mobile no. +91-9897249202 E-Mail: csrameshb@gmail.com

Access this Article online

Quick Response code

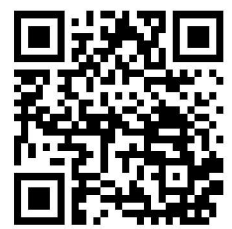

DOI: $10.16965 /$ ijar.2018.361

Journal Information

International Journal of Anatomy and Research

ICV for 2016 ISSN (E) 2321-4287 | ISSN (P) 2321-8967

90.30

https://www.ijmhr.org/ijar.htm

DOI-Prefix: https://dx.doi.org/10.16965/ijar

Article Information

Received: 16 Aug 2018

Peer Review: 16 Aug 2018

Revised: None
Accepted: 03 Oct 2018

Published (O): 05 Nov 2018

Published (P): 05 Nov 2018

\section{INTRODUCTION}

The median nerve (C5-T1) is formed by the union of a medial root from the medial cord (C8- T1) and a lateral root from the lateral cord (C5- C7) of the brachial plexus. The text book description is that formation of the median nerve is either anterior or lateral to third part of the axillary artery [1]

Several variations about median nerve in terms of number of roots or position and distance of union of the roots have been reported.

Badawoud (2003) showed 4 types of anomalies in the median nerve formation found on 48 upper extremities of 24 cadavers. They found 
anomalies (usually on the left side) which comprised of communicating branches between lateral and medial roots of the median nerve, a communicating branch between lateral root of the median nerve and the medial cord of the brachial plexus, communicating branches between lateral root of the median nerve and musculocutaneous nerve and unusually long roots of the median nerve [2]. Aggarwal et al (2009) described rare anomalous formation of the left median nerve by union of two medial and two lateral roots [3]. Several other authors have reported and explained such kind of variations and their embryological basis $[4,5]$.

Variations in the formation of median nerve are clinically important to understand the abnormal presentation of clinical signs in cases of nerve injury; it is also helpful for surgeons to know about these variations during axillary explorations.

\section{MATERIALS AND METHODS}

The present study was conducted during routine dissection of 34 preserved cadavers and 10 isolated upper limb specimens in order to find out variations of roots/ communications of median nerve. All cadavers were conventionally dissected and observed for median nerve formation and dissected up to cubital fossa for presence of any communication.

\section{OBSERVATIONS}

Of the 78 upper limbs (40 right and 38 left limbs) dissected, 12 limbs (15.38\%) showed two lateral roots and one medial root contributing to the formation of median nerve. One case of bilateral presence of extra lateral root was found. Out of these twelve cases, in two cases a second lateral root or communication was coming from musculocutaneous nerve after piercing the coracobrachialis and in rest 10 cases the second lateral root or communication was joining the median nerve before coracobrachialis $\{$ Fig-1,2 $\}$. In three cases absence of musculocutaneous nerve was observed. In one case of absent musculocutaneous nerve, muscles of flexor compartment of arm were supplied by median nerve itself which also gave the lateral cutaneous nerve of forearm. In the rest of the two cases, the median nerve supplied the flexor
Fig. 1: Left upper limb showing median nerve (MN) formation by two lateral roots (LR-1, LR-2). The second lateral root (LR-2) is joining the median nerve before coracobrachialis muscle. AA- Axillary artery; LC- Lateral cord; MC- Medial Cord; MCN- Musculocutaneous nerve.

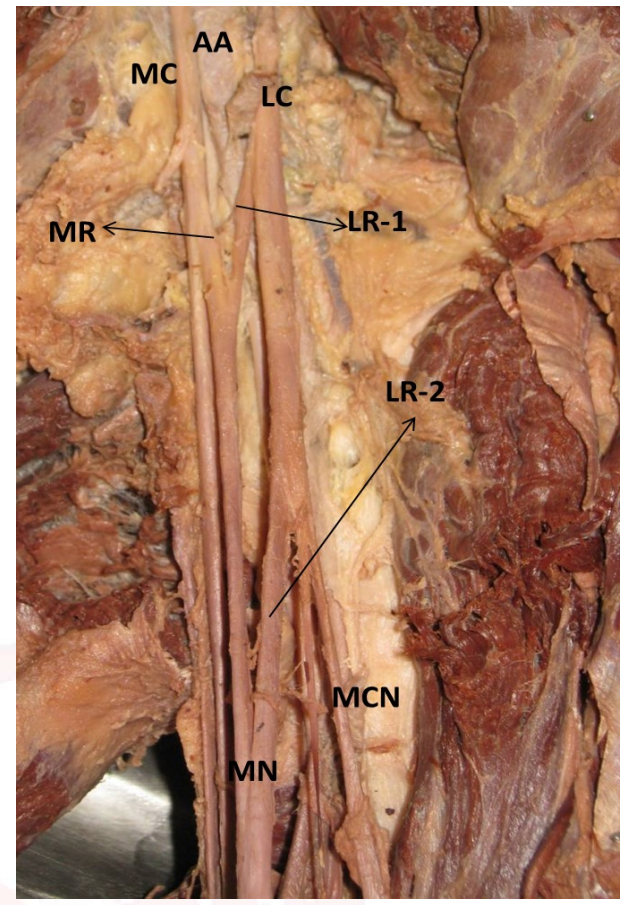

Fig. 2: Right upper limb showing the second lateral root (LR-2) / communication arising from musculocutaneous nerve (MCN) after the nerve has come out of the coracobrachialis muscle (CB). UN- Ulnar nerve

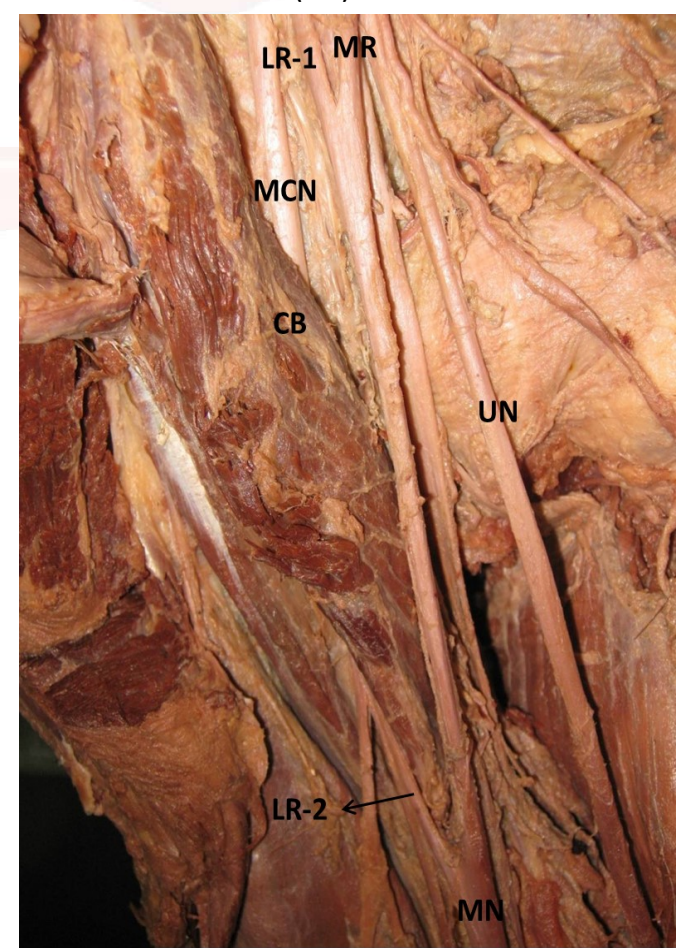

compartment muscles except coracobrachialis, which is known as partial absence of the musculocutaneous nerve \{Fig.3\}. One of the cases of absent musculocutaneous nerve had two medial roots and one lateral root, that is a very rare combination of variations $\{$ Fig. 4$\}$. 
Vinay Sharma, C.S. Ramesh Babu, Vishnu Gupta. VARIATION OF ROOTS IN THE FORMATION OF MEDIAN NERVE.

Along with this case one more case of two medial roots and one lateral root was also noticed \{Fig.5\}.

In all cases of two lateral roots or communication, the median nerve was formed medial or anterior to axillary artery. So we observed

Fig. 3: Right upper limb showing partial absence of Musculocutaneous nerve with median nerve (MN) supplying Biceps brachii (BB) and Brachialis muscles and giving lateral cutaneous nerve of forearm (LCN).

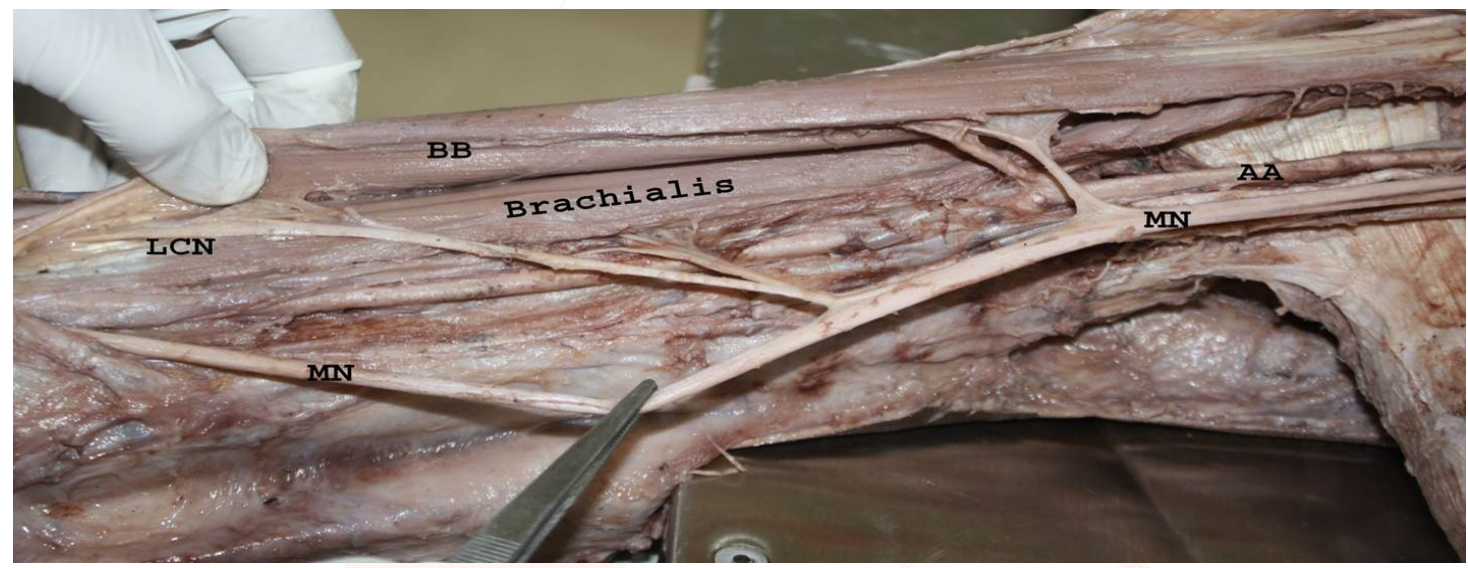

Fig. 4: Right upper limb showing complete absence of musculocutaneous nerve and formation of median nerve $(\mathrm{MN})$ by three roots, one lateral (LR-MN) and two medial roots (MR-1, MR-2). The median nerve is giving branches to Coracobrachialis $(\mathrm{Br}-\mathrm{CB})$, Biceps brachii $(\mathrm{Br}-\mathrm{BB})$ and Brachialis $(\mathrm{Br}-\mathrm{B})$. The branch to brachialis continued as lateral cutaneous nerve of forearm.

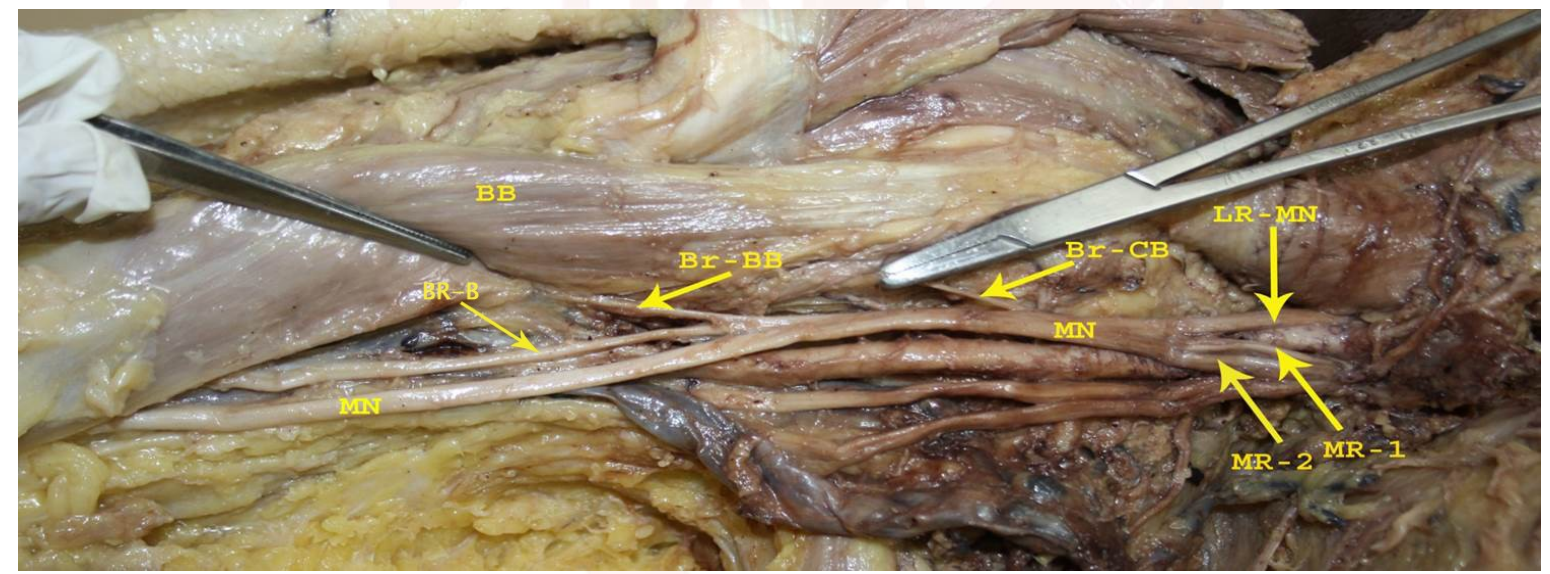

Fig. 5: Right upper limb showing formation of median nerve by three roots, one lateral (LRMN) and two medial roots (MRMN-1, MRMN-2). In this case the musculocutaneous nerve (MCN) was normally arising from lateral cord and piercing the Coracobrachialis muscle. * indicates anomalous common trunk of subscapular, thoracoacromial and lateral thoracic arteries arising from axillary artery (AA).

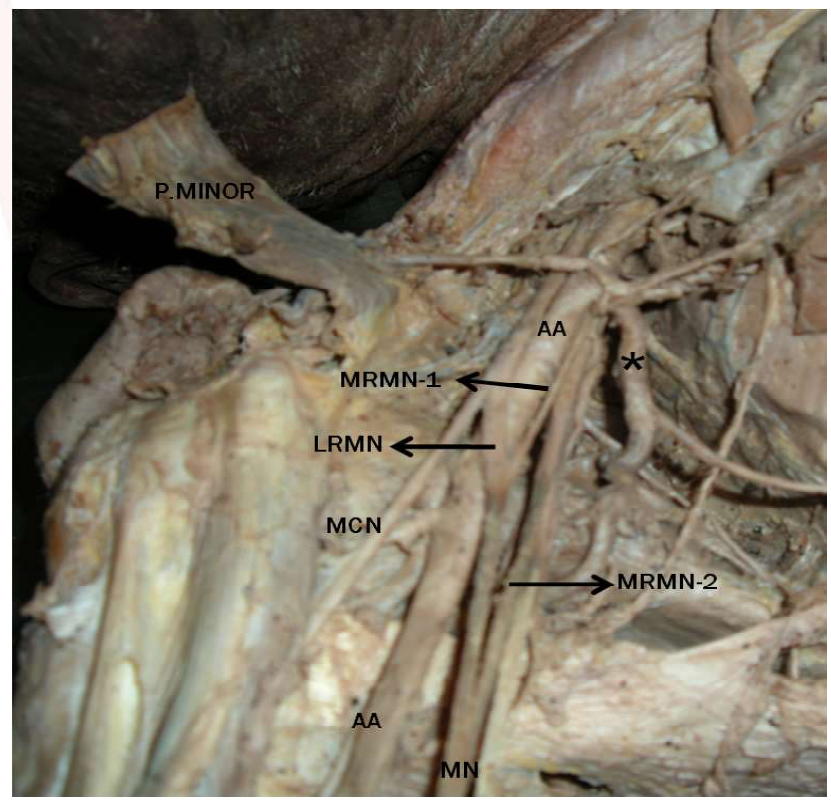


Vinay Sharma, C.S. Ramesh Babu, Vishnu Gupta. VARIATION OF ROOTS IN THE FORMATION OF MEDIAN NERVE.

Table 1: Comparison of different studies of variation of roots of median nerve

\begin{tabular}{|c|c|c|c|c|c|c|}
\hline Authors & $\begin{array}{l}\text { Total } \\
\text { cases }\end{array}$ & $\begin{array}{c}\text { Communication } \\
\text { between MCN and } \\
\text { MN }\end{array}$ & $\begin{array}{c}\text { Absence of musculocutaneous nerve } \\
\text { (fusion of MCN fibers with MN) }\end{array}$ & $\begin{array}{l}\text { Single Lateral root arising from } \\
\text { MCN distal to coracobrachialis }\end{array}$ & $\begin{array}{c}\text { MN formation by double } \\
\text { medial root and single } \\
\text { lateral root }\end{array}$ & Any other Specific findings \\
\hline Samarawickrama, M. B (2017) [6] & 98 & $6(6.12 \%)$ & $01(1.02 \%)$ & nil & $01(1.02 \%)$ & $\begin{array}{l}\text { One case of three lateral and one medial } \\
\text { root }\end{array}$ \\
\hline Master NT. et al (2016) [4] & 56 & $07(12.5 \%)$ & $01(1.78 \%)$ & $02(3.57)$ & Nil & $\begin{array}{c}\text { Out of seven cases of MCN and MN } \\
\text { communication, the branch was proximal to } \\
\text { coracobrachialis in one case and distal in } 6 \\
\text { cases }\end{array}$ \\
\hline P Chaudhary (2013) [5] & 60 & $06(10 \%)$ & $06(10 \%), 4$ complete and two partial & Nil & nil & $\begin{array}{l}\text { all communication or second root proximal } \\
\text { to coracobrachialis }\end{array}$ \\
\hline Present study & 78 & $12(15.38 \%)$ & $3(3.84 \%)$ one complete and two partial & Nil & $2(2.56 \%)$ & $\begin{array}{c}\text { Case of absence of MCN was also shared by } \\
\text { double medial root case }\end{array}$ \\
\hline
\end{tabular}

Fig. 6: Schematic diagram showing Le Minor's Classification of Median and Musculocutaneous nerve variations into five types. B- Brachialis; BB- Biceps brachii; CB- Coracobrachialis; Com- Communicating branch; LC- Lateral Cord; LR- Lateral Root; MC- Medial cord; MN- Median Nerve; MCN- Musculocutaneous nerve; MC- Medial cord. MR- Medial Root; UN- Ulnar nerve. Small arrows represent the position of entry of MCN into coracobrachialis muscle.

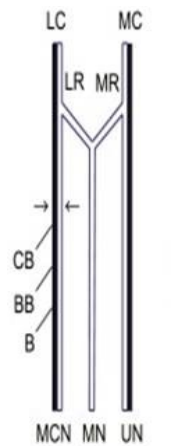

(I)

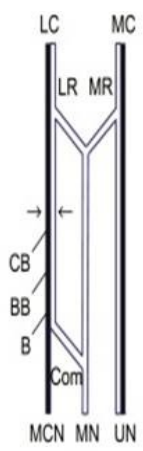

(II)

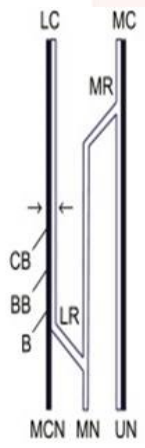

(III)

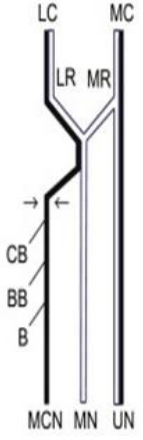

(IV)

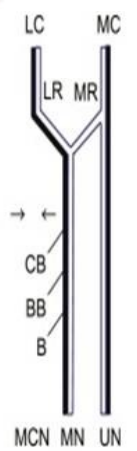

(V)

\section{DISCUSSION}

Variations in median nerve formation by an extra root or complete fusion of musculocutaneous nerve with median nerve in our study was observed in 16 out of $78 \mathrm{limbs}$ (20.51\%). Out of these, 12 cases (15.38\%) of two lateral and one medial root forming the median nerve, 3 cases of complete or partial absence of musculocutaneous nerve $(3.84 \%)$ and 2 cases of formation of median nerve with two medial roots and one lateral root were present (2.56\%). One case of two medial roots and one lateral root was shared by absence of musculocutaneous nerve. Observations of the present study were very similar to Samarawickrama M. B (2017) who observed median nerve variation in 98 upper limbs focusing on the variation of the roots and relation to the arteries [6]. Total variations of MN formation were observed in 33 (33.67\%) upper limbs and the variations were divided broadly in to two groups, variation of roots (15.3\%) and variation of arterial relations (18.37\%). He observed three roots formation of median nerve with two lateral roots and one medial root in 6 cases $(6.12 \%)$, three root formation with two medial and one lateral root in one case (1.02\%) and absent musculocutaneous nerve in one case (1.02\%). He also observed formation of median nerve by four roots, three laterals and one medial root in $2.04 \%$ cases. We did not notice such formation of the median nerve by more than three roots in our study. He also noticed absent musculocutaneous nerve in one case $(1.02 \%)$ and these findings were very similar to the present study.

Results of the present study were similar to the findings of Master NT. et al (2016) who noticed in their study of 56 upper limbs, different types of variations in the formation of the median nerve in 12 upper limbs (21.43\%). In 6 upper limbs communicating rami were present below the coracobrachialis muscle. In 1 upper limb musculocutaneous nerve was not piercing the coracobrachialis muscle and was giving a large communicating ramus to the median nerve as the third root at the level of coracobrachialis. In one upper limb the musculocutaneous nerve completely fused with the median nerve after supplying coracobrachialis [4]. In 2 limbs the medial cord continued as median nerve and musculocutaneous nerve gave the lateral root distal to coracobrachialis. In 2 limbs MCN was completely absent and all brachial flexors supplied by median nerve.

Chaudhary P. et al (2013) observed absent musculocutaneous nerve in six out of $60 \mathrm{limbs}$ studied (10\%). A single communication between 
the musculocutaneous and the median nerve was present in the six limbs (10\%). It was in the upper third of the upper arm, proximal to the entrance of the musculocutaneous nerve into the coracobrachialis muscle [5].

Channabasanagouda et al (2013) reported the formation of median nerve by three roots in $26 \%$ specimens [7].

On the contrary Padur A.A. et al (2016) reported only one case of formation of median nerve by three roots, two lateral and one medial, in a study of 82 upper limbs of 41 cadavers [8].

P. S. Chitra and V. Anandhi (2016) also noted during dissection of 72 upper limbs of $36 \mathrm{ca}$ davers that in both upper limbs of a cadaver, three roots were taking part in the formation of median nerve (2.7\%) [9].

In present study 12 cases of double lateral root or communication between musculocutaneous nerve and median nerve were found (15.38\%). This was considered as the most common variation noticed in median nerve formation by an extra root.

Variant communications between the median and musculocutaneous nerves were classified by Le Minor (1990) into five types [10]. In Type I there is no communication between the median and musculocutaneous nerves. In type II some fibres of lateral root of median nerve pass through musculocutaneous nerve and join the median nerve in the middle of the arm, whereas in type III the lateral root fibres of the median nerve pass along the musculocutaneous nerve and after some distance leave it to form the lateral root of median nerve. In type IV the musculocutaneous nerve fibres join the lateral root of the median nerve and after some distance the musculocutaneous nerve arises from median nerve. In type $V$ the musculocutaneous nerve is absent.\{Fig.6\}

Sixty two cases $(79.49 \%)$ of present study belong to Type I of Le Minor classification that is normal formation of median nerve from one lateral root and one medial root. The musculocutaneous nerve was defined as the rest of lateral cord after branching of lateral root of median nerve so second root emerging can be considered as communication between musculocutaneous and median nerve.
In present study 12 cases of double lateral root or communication between musculocutaneous nerve and median nerve were found (15.38\%). Incidence of variation was very similar to Budhiraja et al (2011) who reported 24 cases of communication between musculocutaneous nerve and median nerve out of 116 upper limbs (20.68\%) [11].Kaur et al (2013) reported communication between musculocutaneous and median nerves in 7 upper limbs in study of 60 upper limbs (11.67\%) [12]

Ballesteros L.E. et al (2015) observed musculocutaneous and median nerve communication in 21 upper limbs in a study of 106 upper limbs (19.8\%) and bilaterally present in 10 upper limbs [13]. Compared to this study we found such communication bilaterally only in a single cadaver. In $17 \%$ cases of the above study, there was musculocutaneous and median nerve communication in which the communicating branch was seen leaving the musculocutaneous nerve after piercing the coracobrachialis muscle and in $2.8 \%$, the connection was before entering the coracobrachialis (Le Minor Type II).

The musculocutaneous and median nerve communication of Le Minor Type II was classified by Venieratos and Anangnostopoulou (1998) into three types in relation to coracobrachialis muscle [14]. In type I, communication was proximal to the entrance of musculocutaneous nerve into coracobrachialis, in type II, distal to the muscle and in type III, neither the nerve nor its branch of communication pierce the muscle.

In 12 cases of double lateral roots or communication between musculocutaneous and median nerves, 10 cases had communication or second root from musculocutaneous nerve before entering the coracobrachialis that is Type 1 of Venieratos and Anangnostopoulous classification In rest of two upper limbs communicating branch or second root was arising from the musculocutaneous nerve after piercing the coracobrachialis similar to Type 2 of this classification. On the contrary Master N T et al (2016) has reported the origin of communicating branch between musculocutaneous and median nerve arising below coracobrachialis muscle in 6 out of 56 limbs (10.7\%) [4]. During dissection of axillary region of a 65-year-old male cadaver Saha and Bhattacharya (2016) noted the lateral 
cord piercing the coracobrachialis muscle where it provided musculocutaneous nerve and lateral root of median nerve. After passing through the muscle, the lateral root gave a branch to coracobrachialis and finally joined with the medial root to form median nerve more distally [15].

Eglseder and Goldman (1997) have found that median nerve was formed from three roots two lateral and one medial root in $14 \%$ of specimens [16]. Uzun and Seelig (2001) noted that the median nerve was formed by four roots, three laterals and one medial root [17]. Chauhan and Roy (2002), Satyanarayana et al. (2010) and Saeed and Rufai (2003) also observed the same variation $[18,19,20]$.

Talhar S et al (2012) and Sakharam et al (2013) observed presence of double lateral roots or communication between musculocutaneous and median nerves bilaterally [21, 22].

In 10 cases of this type, median nerve was formed medial to axillary artery; in fact in last few cases double lateral root was suspected when the median nerve was medial to the axillary artery. Pandey and Shukla (2007) have dissected 172 cadavers and found that the roots of median nerve joined on medial side of axillary artery in $4.7 \%$ cases [23]. Similarly we observed that the cases where median nerve was medial to axillary artery it was mostly associated with an extra lateral root.

In three cases of the present study we observed absence of the musculocutaneous nerve and the median nerve was supplying the flexor compartment muscles. In partial absence of musculocutaneous nerve, the coracobrachialis is supplied by a branch from the lateral cord itself and in complete absence all the flexor muscles of the arm are supplied by median nerve. We have noted partial absence in two cases and complete absence in one case. One case of complete absence of musculocutaneous nerve was associated with the presence of two medial roots which is a very rare variation. To the best of our knowledge, such a combination of variations was not reported in the literature.

Chaudhary P. et al (2013) also noted absent musculocutaneous nerve in $6(10 \%)$ limbs [5]. Yang et al (1995) reported one such case out of 24 cadaveric specimens (4\%) as fusion of median and musculocutaneous nerves [24]. Sarkar and Saha (2014) noted bilateral absence of musculocutaneous nerve and all the flexor muscles of the arm except the coracobrachialis were supplied by the median nerve [25]. Pankaj A.K. et al (2012) also reported absence of musculocutaneous nerve in right arm of 54 years male cadaver and explained the embryological basis [26].

Paranjape V. et al (2012) also reported similar case of absent musculocutaneous nerve and flexor compartment supplied by median nerve [27]. This type of variation was described by Le Minor (1990) as Type V [10].

As the musculocutaneous nerve is absent and the entire fibres of the nerve pass through the lateral root and fibres to the muscles supplied by the musculocutaneous nerve branch out directly from the median nerve. Other authors have also reported the absence of musculocutaneous nerve $[28,29]$.

This type of variation is important because median nerve supplies the flexors of brachium from lateral aspect. Usually median nerve does not give any branch in the arm and if found during surgery of flexor compartment of arm care must be taken to avoid injury to these branches.

In present study two cases of double medial root were noted. This kind of rare variation was not mentioned under Le Minor classification. Samarawickrama, M. B (2017) noted 1 case of double medial root in a study of 98 upper limbs [6]. Patil et al (2012) also noticed two medial and one lateral root forming the median nerve [30].This type of communication or second medial root of median nerve is less noted variation in different studies in comparison of other varieties.

Larson WJ.(2001) explained significant variations in nerve pattern may be the result of altered signalling between the mesenchymal cells and the neuronal growth cones or circulatory factors at the time of formation of brachial plexus cords [31]. Choi et al (2002) described about the significance of these communicating branches in diagnostic clinical neurophysiology [32]. Leffert (1985) emphasized to rule out such communications to prevent the unwanted 
outcome of operations on musculocutaneous nerve [33].

\section{CONCLUSION}

In our study we were able to find out first second and fifth types of Le Minor classification. Present study also demonstrated type I and 2 of Venieratos and Anangnostopoulou classification. But in this study we did not notice any case of type three and type four of Le Minor classification, but two rare cases of double medial root were noticed and this type was not described by any type of classification. One of these cases was associated with absent musculocutaneous nerve which is a very rare variation not reported in the literature. Knowledge of such kind of variations in median nerve formation is important for surgeons and anaesthetist. Such kind of variations can lead to abnormal presentation in entrapment neuropathy and also lead to compression of adjacent vessels leading to symptoms.

\section{Conflicts of Interests: None}

\section{REFERENCES}

[1]. R Chitra. Multiple bilateral neuroanatomical variations of the nerves of the arm. Neuroanatomy. 2007; 6: 43-5.

[2]. Badawoud MHM. A Study on the Anatomical Variations of Median Nerve Formation. Bahrain Medical Bulletin 2003; 25(4).169-171

[3]. Aggarwal A, Harjeet K, Sahni D, Aggarwal A. Bilateral multiple complex variations in the formation and branching pattern of brachial plexus. Surg Radiol Anat 2009; 31(9): 723-731

[4]. Master NT, Gupta SD. Analysis of morphological variation between musculocutaneous nerve and median nerve. Indian J Clin Anat Physiol. 2016; 3 (3): 326-331

[5]. Chaudhary P., Kalsey G., Singla R., Arora K. Communication between musculocutaneous and median nerve -different type and their incidence in north indian population. Indian J Clin Pract. 2013; 24(3): 364-371.

[6]. Samarawickrama MB. A study of anatomical variations of median nerve formation and its relation to the arteries in the axilla and arm. Int. J. Morphol., 2017; 35(2):698-704.

[7]. Channabasanagouda, Shrish P., Shinde V, JevoorP S, Nidoni MA. Study of anatomical variations of median nerve in human cadavers. International Journal of Biomedical Research. 2013; 04 (12):682-690.

[8]. Padur A.A., Kumar N, Shanthakumar S.R., Shetty S.D., Prabhu G.S., Patil J. Unusual and Unique Variant
Branches of Lateral Cord of Brachial Plexus and its Clinical Implications- A Cadaveric Study. J Clin Diagn Res. 2016; 10(4): AC01-AC04.

[9]. Chitra P. S, Anandhi V. A study of the different types of formation of the median nerve. Int J Anat Res. 2016; 4(2):2397-2400.

[10]. Le Minor JM. A rare variation of the median and musculocutaneous nerves in man. Arch Anat Histol Embryol. 1990;73:33-42

[11]. Budhiraja V, Rastogi R, Asthana AK, Sinha P, Krishna A, Trivedi V. Concurrent variations of median and musculocutaneous nerves and their clinical correlation- a cadaveric study, Italian J Anat and Embryol IJAE , 2011, 116 (2): 67- 72.

[12]. Kaur N, Singla RK. Different types of communications between musculocutaneous nerve and median nerve -a cadaveric study in north Indian population. CIBTech J Surg. 2013; 2 (1): 21-28.

[13]. Ballesteros L.E, Forero P.L., Edna, Buitrago R.- Communication between the musculocutaneous and median nerves in the arm: an anatomical study and clinical implications Rev Bras Ortop. 2015; 50(5):567-572

[14]. Venieratos, D., Anagnostopoulou, S. Classification of communications between the musculocutaneous and median nerves. Clin Anat. 1998; 11:327-331.

[15]. Saha D., Bhattacharya B. Variation in Formation of Median and Musculocutaneous Nerves and their Unusual Branches - A case study, Indian Journal of Basic and Applied Medical Research; 2016: 5,(4): 111-115

[16]. Eglseder E, Goldman M. Anatomical Variations of the Musculocutaneous Nerve in the Arm. Am J Orthop 1997; 26(11):777-80.

[17]. Uzun A, Seelig LL Jr A variation in the formation of the median nerve; communicating branch between the musculocutaneous and median nerves in man. Folia Morphol (Warsz) 2001; 80: 99-101.

[18]. Chauhan R, Roy TS. Communication between the median and musculocutaneous nerve- a case report. Journal of the Anatomical Society of India.2002: 52(1): 72-5.

[19]. Satyanarayana N, Reddy CK, Sunitha P, Jayasri N, Nitin V, Praveen G, Guha R, Datta AK, Shaik MM Formation of median nerve by three roots - a case report. J College of Medical Sci-Nepal 2010; 6: 47-50.

[20]. Saeed M, Rufai AA- Median nerve and musculocutaneous nerves: variant formation and distribution. Clinical Anatomy.2003: 16: 453-7

[21]. Talhar S., Sontakke B. R., Bokariya P., Tarnekar A.M., ShendeM. R., Bilateral Variation in Formation of Median Nerve. IOSR Journal of Pharmacy. 2012; 2 (6): 05-07.

[22]. Sakharam R.R., Mahadeo D.J., Sacchidanand J.S., Mahadeo P.S., Bilateral presence of third root of median nerve: a case report, International Journal of Anatomical Variations. 2013; 6: 74-76

[23]. Pandey SK, Shukla VK. Anatomical variations of the cords of brachial plexus and the median nerve. Clin Anat. 2007; 20: 150-156. 
Vinay Sharma, C.S. Ramesh Babu, Vishnu Gupta. VARIATION OF ROOTS IN THE FORMATION OF MEDIAN NERVE.

[24]. Yang ZX, Pho RW, Kour AK, Pereira BP. The musculocutaneous nerve and its branches to the biceps and brachialis muscles. J Hand Surg Am 1995;20(4):6715.

[25]. Sarkar A, Saha A. Bilateral Absence of Musculocutaneous Nerve: A Case Report, Journal of Clinical and Diagnostic Research. 2014; 8(9): AD06-AD07.

[26]. Pankaj A.K., Ramesh BabuCS, Rani A, Rani A, Chopra J, Verma R.K., Kumar N, SrivastavaAK. Absence of musculocutaneous nerve: Embryological basis. Asian Journal of Medical Sciences 2012; 3: 21-24

[27]. Paranjape V, Swamy P.V. and Mudey A,. Variant Median and Absent Musculocutaneous Nerve. J Life Sci, 2012; 4(2): 141-144.

[28]. Bhanu S P.,Devishanker K. Bilateral absence of musculocutaneous nerve with unusual pattern of lateral cord and median nerve of brachial plexus .Anat. Cell Biol.2012; 45:207-10

[29]. Ravishankar M.V., Jevoor P.S., Saha I. Bilateral absence of musculocutaneous nerve, J Sci Soc 2012 ; 39(1) 34-36
[30]. .Patil D.A., Jadhav A.S., Bhingardeve C.V., Katti A.S. Variation in the formation, communication and distribution of median nerve: a cadaveric study, Asian Pac. J. Health Sci., 2016; 3 (4):17-22

[31]. Larson WJ. Development of peripheral nervous system.3rd ed. Pennsylvania: Churchill Livingstone, 2001, 115-156.

[32]. Choi D, Rodríguez-Niedenführ M, Vázquez T, Parkin I, Sañudo JR. Patterns of connections between the musculocutaneous and median nerves in the axilla and arm. Clin Anat 2002;15(1):11-7.

[33]. Leffert RD. Brachial plexus injuries. In: Anatomy of the Brachial Plexus. Churchill Livingstone: New York 1985:p.384.

\footnotetext{
How to cite this article:

Vinay Sharma, C.S. Ramesh Babu, Vishnu Gupta. VARIATION OF ROOTS IN THE FORMATION OF MEDIAN NERVE. Int J Anat Res 2018;6(4.2):5853-5860. DOI: 10.16965/ijar.2018.361
} 